\title{
Dilemas e aporias subjacentes aos processos de implementação da Lei $10.639 / 2003^{1}$
}

\section{Dilemmas and aporias underlying the processes of implementation of Law 10.639/2003}

\author{
Moisés de Melo Santana ${ }^{2}$ \\ Itacir Marques da $\mathrm{Luz}^{3}$ \\ Auxiliadora Maria Martins da Silva ${ }^{4}$
}

\begin{abstract}
RESUMO
Este artigo reflete sobre os dilemas e as aporias subjacentes aos processos de implementação da Lei 10.639/2003 reafirmados na pesquisa "Práticas Pedagógicas de Trabalho com Relações Étnico-Raciais na Perspectiva da Lei 10.639/2003" na região NE II, envolvendo os Estados de Pernambuco, Paraíba, Alagoas, Piauí e Rio Grande do Norte, realizada em 2009 pela UNESCO e MEC - Ministério da Educação - e coordenada pelo Programa de Ações Afirmativas da UFMG. A pesquisa foi de cunho qualitativo, utilizou procedimentos metodológicos de análise documental, entrevistas e observações de campo. A perspectiva teórica que referendou as análises foi o transculturalismo crítico, em fase de constituição. Os autores que têm referendado essa perspectiva são Santos (2003), Santana (2000), Assmann (1994), Benjamin (1994), Hall (2003), McLaren (1993), Munanga (1996a, 1996b, 1996c), Tinhorão (1991) e Todorov (1999). Os resultados do traba-
\end{abstract}

\footnotetext{
${ }^{1}$ Este trabalho foi submetido à $35^{\mathrm{a}}$ Reunião Anual da Associação Nacional de Pós-Graduação e Pesquisa em Educação - ANPEd.

${ }^{2}$ Doutor em Educação pela Pontifícia Universidade Católica de São Paulo. Professor Adjunto da Universidade Federal Rural de Pernambuco, Brasil. E-mail: moises75@hotmail.com

${ }^{3}$ Mestre em Educação pela Universidade Federal da Paraíba e doutorando na Universidade Federal de Minas Gerais, Brasil. E-mail: itacirluz@hotmail.com

${ }^{4}$ Doutora em Educação pela Universidade Federal de Pernambuco, Brasil. E-mail: auxiliadora.martins@ig.com.br
} 
lho indicam que a Educação das Relações Étnico-Raciais só superará seus dilemas e aporias fundamentais quando a educação escolarizada incorporar efetivamente o princípio da diversidade cultural humana enquanto eixo orientador das práticas educativas escolarizadas. $\mathrm{O}$ trabalhou também apontou para a necessidade de o Estado desenvolver programas estruturadores que articulem os processos de formação inicial e continuada de professoras/es com os Núcleos de Estudos Afro-Brasileiros e os Grupos de Trabalho das Secretarias Estaduais e Municipais de Educação que tratam da Educação das Relações Étnico-Raciais.

Palavras-chave: Educação; Lei 10.639/2003; transculturalismo crítico; relações étnico-raciais.

\begin{abstract}
This article reflects on the dilemmas and aporias underlying the processes of implementation of Law 10.639/2003 reaffirmed in research "Pedagogical practices with ethnic-racial relations in the school from the perspective of Law 10.639/2003" in NE region II, involving the States of Pernambuco, Paraíba, Alagoas, Piauí and Rio Grande do Norte performed in 2009 by UNESCO and MEC - Ministry of Education and coordinated by the Affirmative Action Program of UFMG. The research was qualitative, and used the methodological procedures of document analysis, interviews and field observations. The theoretical perspective endorsing the analysis was the critic transculturalism in the constitution stage. Authors who have endorsed this perspective are Santos (2003), Santana (2000), Assmann (1994), Benjamin (1994), Hall (2003), McLaren (1993), Munanga (1996a, 1996b, 1996c), Tinhorão (1991) and Todorov (1999). The results indicate that the Education of Ethnic-Racial Relations is only going to overcome their dilemmas and fundamental aporias, when the school education effectively incorporate the principle of human cultural diversity as the guiding axis of educational practices. This work also pointed to the State's need to develop structuring programs that articulate the processes of initial and continued training of teachers with the Centers of Afro-Brazilian Studies and the Working Groups of the state and municipal departments of Education dealing with Ethnic-Racial Educational Relations.
\end{abstract}

Keywords: Education; Law 10.639/2003; critic transculturalism; ethnicracial relations. 


\section{Introdução}

A pesquisa objetivava identificar experiências exitosas de implementação da Lei 10.639/2003 nas escolas públicas brasileiras, considerando as práticas pedagógicas, os processos de formação continuada e a introdução da temática racial como eixo orientador do Projeto Político-Pedagógico.

Os procedimentos metodológicos desenvolvidos fazem parte do que foi estabelecido para as demais coordenações: selecionar dentre as trinta escolas indicadas pela Coordenação Nacional, a partir de um amplo levantamento de dados junto aos Núcleos de Estudos Afro-Brasileiros, às Secretarias Estaduais e Municipais de Educação e à base de dados do Centro de Estudos das Relações de Trabalho e Desigualdades (prêmio CEERT), seis escolas por meio da aplicação de questionário de checagem aplicado via telefone aos gestores de trinta escolas.

A escolha das escolas foi realizada rigorosamente com base nos critérios estabelecidos a fim de contemplar as diferentes modalidades de ensino, a participação dos/as professores/as em processos de formação continuada, a participação coletiva dos/as professores/as no planejamento das atividades de ensino-aprendizagem, o envolvimento da escola com movimentos sociais, grupos culturais e a comunidade do entorno, de ter sido indicada pelas diferentes instituições que foram consultadas na primeira fase da pesquisa e responderam o questionário.

As seis escolas selecionadas foram a base para a realização do trabalho de campo. A regional NE II selecionou as seguintes instituições:

1. Escola Professora Josefa Botelho, Natal - Rio Grande do Norte, indicada pela Secretaria Municipal de Educação - SEMED;

2. Creche - Escola Meimei, Olinda - Pernambuco, indicada pelo CEERT;

3. Escola Estadual Monsenhor Luiz Carlos de Oliveira Barbosa, Ibateguara - Alagoas, indicada pela Secretaria de Estadual de Educação - SEE;

4. Escola Estadual Zacarias de Góis/Liceu Piauiense, Teresina - Piauí, indicada pelo CEERT;

5. Escola Estadual Monsenhor Clóvis Duarte de Barros/Escola Municipal Jairo Correia, União dos Palmares - Alagoas, indicadas pelo Núcleo de Estudos Afro-Brasileiros - NEAB/UFAL;

6. Escola Municipal Zumbi dos Palmares, Maceió - Alagoas, indicada pelo NEAB/UFAL. 
O trabalho de campo foi realizado durante dois meses. A ida a campo foi precedida pelo trabalho de levantamento de dados e informações para subsidiar a realização das visitas às escolas. Os pesquisadores que realizaram o trabalho de campo sistematizaram e organizaram um relatório preliminar que foi objeto de apresentação e discussão.

\section{Principais resultados}

Constatamos que o processo de institucionalização da Lei 10.639/2003 nas redes de ensino ainda é frágil. Os procedimentos de levantamento de dados iniciais, encaminhados para os gestores municipais e estaduais, que não foram respondidos, demonstram ou indicam o grau de institucionalização da lei nas redes de ensino. Esse limite detectado nessa fase da pesquisa pode ser analisado sob a ótica do racismo institucional. Os questionários que não foram respondidos pelos gestores estaduais e municipais impossibilitaram que experiências significativas que estão sendo desenvolvidas em algumas redes fossem visitadas e analisadas.

A sustentabilidade das experiências tem relação com fatores inerentes às redes de ensino públicas e às próprias instituições de ensino. Todavia, é possível afirmar que as escolas que estão desenvolvendo suas experiências articuladas com os Núcleos de Referências das Secretarias Municipais e Estaduais de Ensino e com os Núcleos de Estudos Afro-Brasileiros e que, internamente, desenvolvem processos de planejamento que envolvem coletivamente os professores e os gestores, tendem a produzir experiências pedagogicamente mais significativas e sustentáveis.

Há um conjunto significativo de experiências que dependem das iniciativas de professores isolados. Essas ações muitas vezes conseguem irradiar e disseminar na cultura escolar uma sensibilização para tratar de forma mais apropriada a problemática étnico-racial. Mas, em alguns casos, elas se restringem aos diretamente envolvidos, não sendo possível considerar essas experiências como sustentáveis.

Existem várias experiências que se desenvolvem a partir da nucleação de atividades artístico-culturais de dança e música nas escolas. Essas experiências são criticadas, sendo chamadas, muitas vezes, de folclorização e cristalização da cultura afro-brasileira. No entanto, é necessário nos debruçarmos de maneira menos apressada sobre esse fenômeno. Podemos levantar dois aspectos relacionados a ele com o intuito de ampliar nosso olhar sobre o tema. 
Um desses aspectos se relaciona ao problema da perspectiva que se tem quando se fala em implementação da lei. Muitas vezes, a implementação é pensada como inclusão apenas de conteúdos históricos, literários, sociológicos, ou seja, é um problema de ausência de conteúdos específicos da História da África e da Cultura Afro-Brasileira. Contudo, a ausência diz respeito a algo maior, a um modo de ser e estar no mundo. Essa ausência coloca o desafio de repensarmos a instituição escolar em profundidade. Os modos de ser afro-brasileiros, mesmo sendo diversificados, têm aspectos que os unificam.

A matriz cultural africana, ressignificada no espaço colonial brasileiro, desenvolve-se de forma diferente da cultura portuguesa. Podemos tomar a música e a dança, como exemplos, para imaginarmos as novas formas de produção cultural que estão se processando no interior da formação sociocultural brasileira. Os trabalhos de Tinhorão $(1988,1991)$ possibilitaram o acesso a um rico universo de informações. Num desses trabalhos, o autor analisa os cantos de trabalho dos negros do campo e da cidade.

De acordo com Tinhorão (1988), na África Ocidental, o fato de todos os atos do dia regerem-se por vontade sobrenatural levou os africanos a desenvolverem um complexo ritual que exigia, para diferentes ações, cantos e danças. Mas, as denominadas canções de trabalho assumiram feições distintas na América, pelas próprias condições de trabalho vividas pelos escravizados.

Há uma espécie de divórcio entre a tradição africana e as inesperadas condições de trabalho escravo, levando-os a reelaborarem suas tradições e costumes. Sob a distinta e adversa situação, eles mantêm os cantos de trabalho, mesclando suas línguas com o português, possibilitando a própria ocultação do sentido daquilo que cantavam.

A música ocupava uma centralidade no cotidiano da vida do negro escravizado. Eles desenvolveram uma variedade de cantos de trabalho, talvez como forma de concentrar forças para as árduas tarefas e atenuar o sofrimento corporal. A música e a dança também estavam presentes nas festas e nas vivências religiosas; contudo, muitas vezes, eram reprimidas. ${ }^{5}$

${ }^{5} \mathrm{O}$ ex-governador de Pernambucano escreve sobre as manifestações (música/dança) negras: “[...] o certo seria reprimir uns (os bailes que entendo serem de total reprovação são aqueles que os pretos da Costa da Mina fazem as escondidas, ou em cazas ou roças com huma preta mestra com altar de Ídolos [i e., com ialorixá e peji]) e liberar os outros. E assim realmente aconteceu, uma vez que, logo após tomar conhecimento desse parecer do Conde Pavolide, de 10 de Junho, o ministro Martinho de Melo, já a 4 de julho daquele mesmo ano de 1780, enviava ao governador de Pernambuco um aviso ordenando-lhe a parte de sua magestade 'não permitisse as danças supersticiosas e gentílicas', mas quanto às demais 'dos pretos', ainda que pouco inocentes podiam ser toleradas, com o fim de evitar-se com este menor mal outros males maiores, devendo contudo usar de todos os meios suaves, que a sua prudência lhe sugerisse, para ir destruindo pouco a pouco um divertimento tão contrário aos bons costumes." (COSTA apud TINHORÃO, 1991, p. 44). 
Nos séculos XVIII e XIX, aquilo que os portugueses chamavam genericamente de batuques começava a se delimitar, pois representava uma variedade de práticas religiosas, de lazer, de danças rituais, entre outras que, pouco a pouco, foram assumindo formas específicas.

A participação dos brancos e mestiços nesses batuques foi desenvolvendo um processo de elaboração cultural em que há uma mescla de elementos das culturas africanas com as europeias, possibilitando o surgimento de diversos gêneros musicais e de danças ao longo de nossa história: samba-de-umbigada, samba-canção, samba-choro, maracatu, maxixe, lundu, coco, capoeira, frevo, samba-reggae, entre outros.

Esse processo é central para entendermos como no Brasil contemporâneo está presente um passado-futuro da negritude brasileira. Será que essas questões têm alguma coisa a ver com os nossos currículos escolares? Com a nossa educação do físico desenvolvida no interior do nosso processo educativo?

Na nossa maneira de apreendê-las, essas questões podem nuclear algumas discussões fecundas e contribuir, provocativamente, para repensar práticas e concepções pedagógicas denominadas progressistas.

Esses elementos nos indicam a necessidade de recolocarmos novas questões em pauta. A provocação pós-moderna de reintrodução de uma "lógica nebulosa”, no interior das práticas educativo-culturais, é instigante pelas possibilidades de se trabalhar no entrejogo de certezas e incertezas que, segundo Assman (1996, p. 16), "constitui um aspecto importante no novo cenário epistemológico da educação".

O que Assman chama atenção com base em pesquisas de biocientistas é que na vida há uma constante interpenetração de caos e ordem, equilíbrio. Nesse sentido, o autor aponta para a necessidade de uma "pedagogia plástica e sinuosa que incentive certezas operacionais e preserve incertezas sobre caminhos, para que sejam buscadas e não estejam predefinidas" (ASSMAN, 1996, p. 17).

Ora, a partir dos anos 1970, tivemos um profícuo movimento no sentido de construir uma abordagem crítica no campo educacional. Podemos inclusive afirmar que, lentamente, tivemos a constituição de diferentes concepções educativas críticas, formuladas no interior das diversas práticas educativas, sindicais, nos movimentos sociais e nos cursos de pós-graduação, entre outros.

Na complexa e imbricada relação Orum ${ }^{6}$-Aiye ${ }^{7}$ há uma dinâmica relacional extremamente importante para entendermos a produção de determinados artefatos culturais afro-brasileiros.

\footnotetext{
${ }^{6}$ Orum - "Um dos níveis ou formas de existência: a existência sobrenatural ou não palpável" (BERKENBROCK, 1997, p. 445).

${ }^{7}$ Aiye - "Um dos níveis da existência: a existência física palpável" (BERKENBROCK, 1997, p. 439).
} 
Na cosmovisão yorubana, o universo existe em dois níveis - o Orum e o Aiye -, ou seja, só é possível a existência nesses níveis, em um deles, ou simultaneamente nos dois. Há nesses diferentes níveis os seus habitantes, ou seja, os Ara-Aiye - humanidade, os Ara-Orum - habitantes do Orum, entre eles destacam-se os orixás e os eguns. ${ }^{8}$ No entanto, o Orum é um nível que engloba tudo e todos, o próprio Aiye, "o Aiye não é um nível de existência fora do Orum, mas - para usarmos uma imagem - é como um útero limitado dentro de um corpo sem limites" (BERKENBROCK, 1997, p. 181).

As comunicações entre o Orum e o Aiye são fundamentais para manter a harmonia da existência. Essa comunicação se estabelece no culto e os orixás, basicamente, são os responsáveis pela presença do Orum no Aiye.

Os Itans ${ }^{9}$ falam do tempo em que Orum e Aiye ainda não estavam separados e os habitantes de ambos os lados tinham trânsito entre os dois níveis. Por causa do erro humano aconteceu que os Ara-aiye não mais podem livremente ir para o Orum, a não ser através da morte (BERKENBROCK, 1997, p. 182).

Essa imagem de unidade primordial é essencial para entender aspectos da cultura afro-brasileira, pois há uma busca permanente pela recomposição dessa unidade perdida. O culto seria a tentativa de viabilização dessa unidade primordial, harmônica. Na cosmologia Yorubana, o sistema Orum-Aiye tem como fundamento último Olorum - "Senhor ou dono do Orum. O ser superior no Candomblé e criador do universo. Também chamado Olodumaré" (BERKENBROCK, 1997, p. 444).

Ora, vimos que a existência acontece num fluxo em que o restabelecimento da relação primordial é constante e as forças que fazem tal intermediação estão concentradas e representadas nos diversos orixás. Tais forças do Orum, ao se relacionarem com e no Aiye, se expressam através de uma musicalidade e de movimentos corporais, danças peculiares; cada orixá tem uma dança própria comem e gostam de determinados alimentos, que devem ser preparados dentro

${ }^{8}$ Orixás - "Forças personalizadas da natureza que são cultuadas no Candomblé. Intermediadores das forças de Olorum. Antepassados sobrenaturais dos seres humanos" (BERKENBROCK, 1997, p. 445). Eguns - "Finado, antepassado humano" (BERKENBROCK, 1997, p. 441).

${ }^{9}$ Os Itans são uma espécie de lendas, histórias que são contadas, transmitidas para manter os conhecimentos da tradição religiosa Yorubá. Na sua maioria são transmitidas oralmente, mas já há registro escrito dos Itans. 
de uma ritualística específica; sendo assim, há uma unidade indissociável, organicamente estabelecida entre religiosidade, gastronomia, musicalidade e corporeidade.

No nosso entendimento, essa organicidade é essencial para entendermos alguns artefatos culturais, determinados saberes, a forma como são produzidos nas fronteiras dessa matriz cultural - as festas de largo, a capoeira, o afoxé, o maracatu, o samba, a culinária baiana, entre outros.

O que nos interessa é que tal processo possibilita o desabrochar de vivências humanas não enquadradas facilmente dentro do padrão de racionalidade ocidental, dentro do que é visto como protótipo de normalidade.

Segundo Sodré (1988), por exemplo, o terreiro de candomblé se constitui como um espaço étnico-cultural que acolhe o entrecruzamento de tempos e espaços implicados na socialização do negro. É um espaço onde se guardava todo um patrimônio cultural, uma variedade de formas dramáticas que se desdobravam ludicamente na sociedade mais abrangente. "A força de conviver com a diversidade e integrar as diferenças sem perder o horizonte da matriz simbólica originária é a principal característica do jogo negro. No que diz respeito à música, o blues remete propriamente à matriz" (SODRÉ, 1988, p. 130).

Ora, se fixarmos os nossos olhares na discussão genérica da folclorização, faremos uma análise superficial da presença da dança e da música no espaço escolar. Essa trama tem muito mais a nos dizer e ensinar.

Como um modo de ser que está presente e interfere profundamente nas produções de espaços de convivências, sejam eles lúdicos, religiosos, de trabalho, de produção de conhecimentos, pode ser escolarizado?

Essa indagação nos conduz a outra dimensão do problema. A Educação das Relações Étnico-Raciais, anunciada nas Diretrizes Curriculares Nacionais de História e Cultura Afro-Brasileira e Africana, aponta para alguma forma de se realizar transposições didáticas desse campo de conhecimento e saberes? Como as experiências de implementação da lei das escolas visitadas estão lidando com essa questão, ou seja, com o fenômeno da didatização dos saberes necessários para a educação das relações étnico-raciais? O problema da institucionalização e da sustentabilidade tem relação direta com essa reflexão.

\section{Complexidade dos saberes escolarizados}

Há um problema básico. Quais são os saberes que estão sendo mobilizados e transformados em fenômeno didático? Quais são as esferas que decidem 


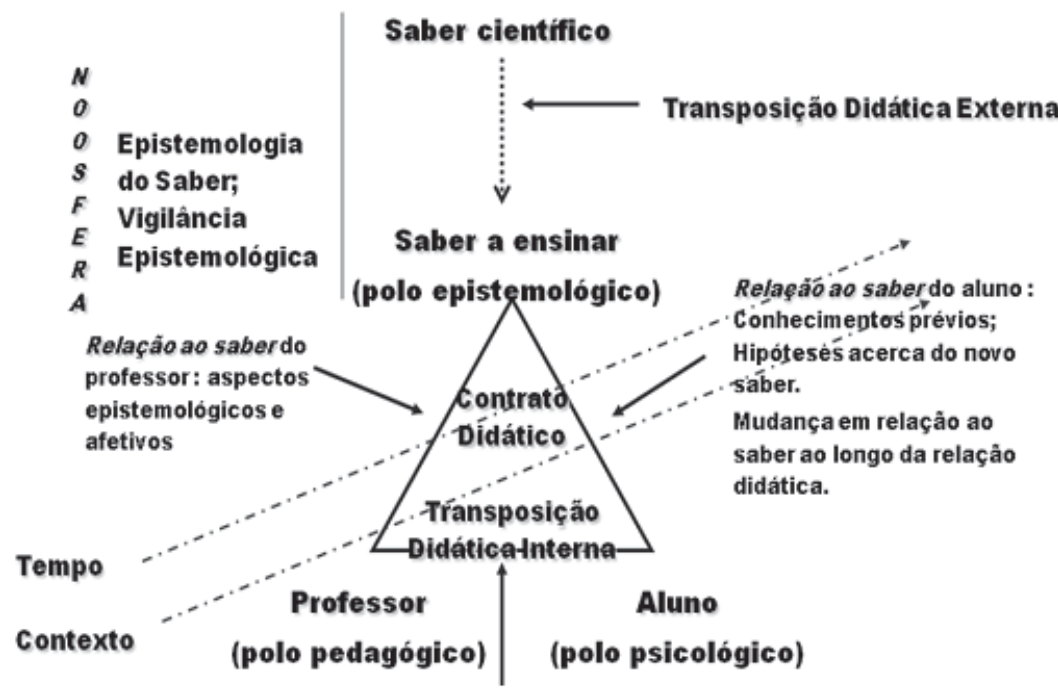

Figura 1 - Triângulo das Situações Didáticas. Elaborado pela Profa. Anna Paula Avelar, da UFRPE, para a Disciplina Metodologia do Ensino Superior, do Programa de Pós-Graduação em Extensão Rural e Desenvolvimento Local.

sobre a legitimidade dos saberes, das formas que eles devem ser didatizados e selecionados? Há um dilema e uma aporia no campo da epistemologia do saber e da vigilância epistemológica que a pesquisa insinua.

Acreditamos que há um aumento das tensões e aporias em torno do desenho predominante de administração/gestão da diversidade cultural brasileira. São vários os fatores que devem ser levados em conta para apreendermos essas tensões. Um deles se refere aos complexos processos de redefinição identitária em curso no mundo, frutos das significativas mudanças que vêm acontecendo desde os finais dos anos 1950 em diferentes planos da vida social. Essas transformações nos possibilitam formular um conjunto de perguntas à educação escolar.

Ora, formular perguntas, provocações, não quer dizer que tenhamos condições de respondê-las de imediato. Desejamos, nesse primeiro momento, aproximar-nos dos problemas sugeridos nos perguntando: residem na instituição escolar possibilidades de transformá-la num complexo institucional interativo, com flexibilidade para dialogar de forma mais dinâmica com outras formas de produção cultural, ou seja, abrir-se num movimento profundo de reestruturação de sua própria institucionalidade?

É possível o currículo escolar ser imaginado como um espaço de confluência de saberes e epistemologias ausentes da escola? É possível que os 
corpos aprendentes possam produzir-se diferente e prazerosamente, na busca de novos caminhos emancipatórios? Ou eles necessariamente são um espaço do mono, do uno, da repetição, mesmo que incorporando, na forma de adereço, novos discursos e metodologias, mas, todavia, mantendo-se inalterada a sua lógica? Quais as experiências efetivas desenvolvidas nos espaços escolares que indicam novos caminhos?

No caso brasileiro, a nossa apartação sociorracial contribui para a produção de espaços antidialogais. Pensamos que esses espaços antidialogais aprofundam o processo de desconhecimento, de falta de interação entre os diferentes brasis. A nossa metáfora "Os brasis não conhecem os brasis..." sintoniza-se com esse aspecto. Apontamos a necessidade de aprofundarmos a discussão em torno de perspectivas pedagógicas que contribuam com a formulação de projetos formativos que efetivamente possibilitem o diálogo e o trânsito entre as diferentes matrizes culturais brasileiras. Esse diálogo poderá ocorrer sugestivamente a partir de uma perspectiva que redesenhe a maneira de perceber e de interagir, nos diferentes espaços educativos. Esses processos formativos mais abertos e criativos devem incorporar a diversidade biossociocultural enquanto um princípio orientador de políticas formativas e curriculares. O processo de implementação da Lei 10.639/2003 mobiliza os saberes e modos de ser que podem contribuir, aprofundar e ressignificar os fazeres cotidianos escolares.

Essa perspectiva exige, do ponto de vista metodológico, um revisitar crítico do próprio lugar do sujeito, suas histórias, memórias, afetos, a fim de poder transitar criticamente por outros lugares. Nesse sentido, o próprio lugar cultural do sujeito é colocado em questão. Essa abordagem não visa à eliminação dos lugares, mas procura potencializá-los. Parte do princípio que não há lugares que devam ser absolutizáveis. Contudo, essa perspectiva metodológica não defende um relativismo generalizável, "em que tudo se equivale desde que se escolha o ponto de vista apropriado: o perspectivismo leva à indiferença e à renúncia a todos os valores" (TODOROV, 1999, p. 304).

Essa abordagem impõe uma aproximação em diferentes planos, como também um diálogo transversal, fecundo, produtivo, entre os brasis. Ela nos convida a conhecer os outros como forma de nos conhecermos. Denominamos de transculturalismo crítico essa perspectiva formativa apontada anteriormente. Então, no nosso entendimento, é necessário articular os conceitos de multiculturalismo, interculturalismo e transculturalismo.

A multiculturalidade é expressão da própria condição humana, ser uno e diverso, capaz de criar, a partir da complexidade cognitiva de que somos portadores, diversos modos de habitar o planeta. Contudo, os processos de 
produção desses modos culturais são constituídos nas relações inter e intraculturais, somos um interser, essencialmente interativo, nos constituímos em interações, ou seja, os processos são interculturais. No entanto, a forma de lidar com os processos nos convida a pensar sobre as perspectivas formativas, as maneiras e modos em que são administradas as relações inter e intraculturais. Nesse sentido, podemos afirmar que os processos institucionais formativos de produção de identidades expressam perspectivas, tendências, mesmo que elas não estejam explicitadas.

O transculturalismo crítico, no seu desenho e esboço inicial, concebe a diversidade biossociocultural enquanto um princípio formativo fundamental, pois expressa tanto a complexidade ecossistêmica quanto a condição ontológica humana, ser portador de possibilidades e produtor de incompletudes culturais. Assim sendo, o diálogo é elemento central, estruturador. Ele exige abertura e conhecimento crítico sobre o outro. É impossível transitar de forma respeitosa sem abertura para dialogar. As relações temporais entre passado, presente e futuro devem ser repensadas, pois não produzimos linearmente a história. A perspectiva historiográfica de Benjamin (1994) pode contribuir com a elaboração desse esboço, rascunho metodológico.

Essas pontuações demonstram que o reexame da história da diversidade cultural, seu processo constitutivo, conflitivo e sua relação com os processos educativos são essenciais. Contudo, além de ser uma tarefa de grande envergadura, é desafiadora, pois a mesma exige uma reapropriação crítica do nosso passado.

As experiências de implementação da Lei 10.639/2003, desenvolvidas a partir de projetos pedagógicos têm possibilitado o desenvolvimento de novos sentidos para os jovens envolvidos, a reeducação de muitos educadores. Mas os professores afirmam que é necessário aprofundar seus conhecimentos para tratar com mais propriedade os temas desenvolvidos nos projetos. Esse aprofundamento não pode ser pensado de maneira estática, mas numa perspectiva de ressignificação crítica das experiências, visando inseri-la no fluxo da história e acordar silenciamentos que dormitam no passado, produzindo novas identidades.

Os grupos de discussão com os estudantes demonstraram que, apesar de as experiências de implementação da Lei 10.639/2003 não estarem consolidadas, existe, por parte dos estudantes, uma postura aberta à diversidade étnico-racial, uma postura crítica diante do preconceito racial. Todavia, o conhecimento sobre o continente africano é superficial. O envolvimento nas atividades de pesquisa revitaliza as vivências escolares. Os alunos gostam do momento escolar das culminâncias de seus trabalhos. 


\section{Considerações finais}

Os resultados da pesquisa apontam para a necessidade do desenvolvimento de ações estruturadoras que consigam contribuir com a institucionalização e sustentabilidade nos processos de implementação da Lei 10.639/2003.

Para Walter Benjamin (1994), nada do que aconteceu pode ser considerado perdido para a história. Ele chama a atenção para os elementos que podem ser negligenciados e, assim, estarem fadados ao esquecimento. Como os elementos revelados no processo de pesquisa podem indicar pistas, sugerir caminhos para que práticas curriculares no interior dos processos de implementação da Lei $10.639 / 2003$ possam efetivar-se concretamente?

Os processos de ressignificação da educação escolarizada hodiernos colocam a necessidade de alterar profundamente as nossas matrizes formativas. Podemos afirmar que construir um Projeto Político-Pedagógico que tenha a diversidade como um foco formativo é essencial para a consolidação de uma mentalidade antirracista, antissexista, anti-homofóbica, igualitária formal e substantivamente. Mas, para tal, será necessário reinventarmos profundamente as instituições formativas no interior da sociedade brasileira. Esse será um dos grandes desafios civilizatórios que teremos que enfrentar.

A pesquisa "Práticas Pedagógicas de Trabalho com Relações Étnico-Raciais na Perspectiva da Lei 10.639/2003" revelou, por um lado, a riqueza dos processos de implementação vividos no sistema público educacional e, por outro, os dilemas e desafios subjacentes a tais processos. A reinvenção e a construção de uma educação pública de qualidade substantivamente democrática, antirracista e aberta à experiência da diversidade cultural humana fazem parte do desafio e da aporia central colocada pela pesquisa.

A partir dos resultados da pesquisa sugerimos:

1. A criação de programas que possibilitem a articulação e o desenvolvimento de uma Rede das Instituições Federais de Ensino Superior que estão oferecendo componentes curriculares relacionados à implementação da Lei 10.639/2003 nas formações iniciais;

2. A criação de uma Política Nacional de Promoção de Núcleos de Referência na implementação da Lei 10.639/2003 nas Secretarias Estaduais e Municipais de Educação, garantindo as condições de funcionamento (liberação de carga horária, espaço físico, recursos);

3. O desenvolvimento de programas que fortaleçam a relação e a articulação entre os Núcleos de Referência das Secretarias Estaduais e Municipais de Educação e os Núcleos de Estudos Afro-Brasileiros; 
4. A criação de concursos temáticos nacionais direcionados às universidades, escolas, gestores, professores e alunos;

5. A inclusão, no Programa Institucional de Iniciação à Docência - PIBID, da exigência das Universidades apresentarem nos seus Planos de Trabalho ações voltadas para implementação da Lei 10.639/2003;

6. A criação de vagas específicas, como as que foram direcionadas para o Ensino de Libras e para a Educação a Distância da Universidade Aberta do Brasil - UAB, nos concursos das Universidades Federais para História da África e Educação das Relações Étnico-Raciais.

\section{REFERÊNCIAS}

ASSMANN, Hugo. Paradigmas educacionais e corporeidade. Piracicaba: UNIMEP, 1994.

Pós-modernidade e agir pedagógico: como reencantar a educação. In: ENCONTRO NACIONAL DE DIDÁTICA E PRÁTICA DO ENSINO, 7., 1996. [Trabalho apresentado]. Florianópolis, 1996. s.n.t.

BARBOSA, Fernancio. História do movimento negro do Piauí. Disponível em: <http:// www.webartigos.com/articles/11154/1/movimento-negro-no-piaui/paginal.html . Acesso em: 03/09/2009.

BENJAMIN, Walter. Magia e técnica, arte e política: ensaios sobre literatura e história da cultura. 7 ed. São Paulo: Brasiliense, 1994. (Obras Escolhidas, v. 1).

BERKENBROCK, Volney. A experiência dos orixás: um estudo sobre a experiência religiosa no candomblé. Petrópolis: Vozes, 1997.

BRASIL. Presidência da República. Lei 10.639, de 9 de janeiro de 2003. Altera a Lei 9.394, de 20 de dezembro de 1996, que estabelece as diretrizes e bases da educação nacional, para incluir no currículo oficial da Rede de Ensino a obrigatoriedade da temática "História e Cultura Afro-Brasileira", e dá outras providências. Disponível em: <http:// www.planalto.gov.br/ccivil_03/leis/2003/L10.639.htm>. Acesso em: 23/06/2012.

. Ministério da Educação/Secretaria de Educação Continuada, Alfabetização e Diversidade. Diretrizes Curriculares Nacionais para a Educação das Relações Étnico-Raciais e para o Ensino de História e Cultura Afro-Brasileira e Africana. Brasília, 2004.

HALL, Stuart. Da diáspora: identidades e mediações culturais. Belo Horizonte: Editora da UFMG; Brasília: UNESCO, 2003. 
McLAREN, Peter. Pós-colonialismo e pedagogia. In: SILVA, Tomaz Tadeu da (Org.). Teoria educacional crítica em tempos pós-modernos. Porto Alegre: Artes Médicas, 1993. . Multiculturalismo crítico. São Paulo: Cortez, 1997.

MUNANGA, Kabengele. Mestiçagem e experiências interculturais no Brasil. In: SCHWARCZ, Lilia Moritz; REIS, Letícia de Souza (Orgs.). Negras imagens. São Paulo: Editora da Universidade de São Paulo/Estação Ciência, 1996a. . As facetas de racismo silenciado. In: SCHWARCZ, Lilia Moritz; QUEIROZ, Renato da Silva (Orgs.). Raça e diversidade. São Paulo: EDUSP/Estação Ciência, 1996b. . O antirracismo no Brasil. In: MUNANGA, Kabengele (Org.). Estratégias e políticas de combate à discriminação racial. São Paulo: EDUSP/Estação Ciência, 1996c.

SODRÉ, Muniz. O terreiro e a cidade: a forma social negro-brasileira. Petrópolis: Vozes, 1988.

SANTANA, Moisés de Melo. Olodum: curricularidade em ritmo de samba-reggae - carnavalizando a educação. Tese (Doutorado) - Pontifícia Universidade de São Paulo-PUC/ SP. São Paulo: PUC/SP, 2000.

SANTOS, Boaventura Sousa (Org.). Reconhecer para libertar: os caminhos do cosmopolitismo multicultural. Rio de Janeiro: Civilização Brasileira, 2003.

TINHORÃO, José Ramos. Os sons negros no Brasil. São Paulo: Art Editora, 1988.

. Pequena história da música popular: da modinha à lambada. 6. ed. rev. e aum. São Paulo: Art Editora, 1991.

TODOROV, Tzvetan. A conquista da América: a questão do outro. 2. ed. São Paulo: Martins Fontes, 1999.

Texto recebido em 16 de abril de 2012.

Texto aprovado em 12 de junho de 2012. 